\title{
Luz y Sombras de Goya: Un Estudio Psicoanalítico
}

\author{
Por el Dr. C. ALBERTO SEGUIN.
}

Tarea difícil es la de ésta conferencia y ello por dos motivos fundamentales. Ante todo, porque los oradores que me han precedido se han ocupado de todas las facetas de la vida, la personalidad y el arte de Goya y lo han hecho con un conocimiento y una erudición que parecen dejar muy poco para agregar. Y, para añadir dificultad a la dificultad, lo que yo voy a decir, encarado desde el punto de vista de la disciplina psicoanalítica, no tiene nada de agradable, placentero, o fácil. Por el contrario, un estudio de está clase nos lleva por senderos escabrosos y difíciles, a veces por rutas desagradables hacia abismos hórridos en los que nos encontraremos cara a cara con ese aspecto "humano, demasiado humano", que se encuentra en todo hombre y que muchas veces, como en el caso de Goya, impregna gran parte de la obra y le da características propias.

Mucho se ha reprochado al psicoanálisis el haberse atrevido a tomar como objeto de investigación la obra de arte y el artista y ello en nombre de una equivocada generalización. Nada mejor que las palabras con que Freud abre su estudio sobre Leonardo da Vinci para destruir esas superficiales críticas : "No tiende -l estudio psicoanalítico, dice el maestro- a oscurecer lo radiante y derribar lo elevado, ni en. cuentra satisfacción ninguna en aminorar la distancia entre la perfección del gran hombre y la insuficiencia de su objeto humano acostumbrado. Por el contrario, abriga un extraordinario interés por todo aquello que tales modelos puedan descubrirle y opina que nadie es tan grande que pueda avergonzarse de hallarse sometido a aquellas leyes que rigen con idéntico rigor tanto la actividad normal como la patológica". 
Estas líneas parecen escritas para Goya. Genio indiscutible que, al decir de Lafont, "se encuentra cien años a la vanguardia de su siglo". juicio que confirma Mayer al opinar que "su obra se proyecta en el crite del siglo siguiente" y Mc Mahon, cuando manifiesta: "lo moderno no se debe todo a Goya, pero, naciendo de él, es una marea que aún asciende", no por ello deja de ser un hombre atado a la tierra y a la vida y extrayendo de ella la inspiración y la fuerza. "Si Goya fué un hombre excepcional entre los grandes, como pintor -dice Francisco de Alcúntara - lo fué sin duda también como hombre vigoroso, fuerte, activo e incansable gustador de los placeres del vivir. Conservó hasta la más extrema vejez una ilusión juvenil de la vida, una sensibilidad exquisita y despierta, una apetencia de goces, que tal vez sólo admita comparación con el caso de Lope. Parece que en Goya, en la sangre de Goya, predomina el elemento ibérico, tal vez el vasco, sin duda celtíbero. Posee toda la dureza del terruño peninsular montañez; es díscolo, rebelde, plebeyo por temperamento; plebeyez susceptible de ser elevada al más alto aristocratismo, a ese aristocratismo de los creadores de las altas dinastías del espiritu y del sentimiento, que arrojan continua y perdurablemente la luz pura de su alma, de su sensibilidad, sobre los rebaños humanos. Goya es un plebeyo, el más plebeyo de todos los artistas, por el recio estómago y el fuerte paladar, por la audacia con que arrastró por la corteza terrestre cuanto en ésta anida de vulgarismo de pasión, de cóleras y de vengativa justicia; pero es, a la vez, el gran aristócrata del arte porque levantó todoesto hastalas alturas purificadoras, hasta donde sólo llegan, de las miseriasiy grandezas humanas la cifra, el signo, el lamento doloroso, la exclamación mística o el himno".

Y Stokes confirma, hablando de él: "En la constitución de cada artista o autor de fuerza viril se encuentra escondida una vena de vulgaridad que constituye una parte esencial del bagaje de su intelecto" . "Según la salud y aliento intelectual del artista la vulgaridad aumenta - disminuye, abruma o deforma su obra y se convierte en debilidad o aparece simplemente de tiempo en tiempo, dando un mayor poder a la creación".

Todo esto se revela, naturalmente, en la obra de arte. Al contemplar los grabados que hoy se exhiben en esta magnífica exposición, penetramos en un mundo extraño: luces hirientes, que desnudan e insultan, oscuridad dantesca, que esconde fantasmas, sombría arquitectura de paredes inverosímiles y arcos que se cierran como mandíbulas; paisajes absurdos con árboles muertos y rocas amenazantes y colinas de infierno, todo ello sirviendo de fondo a personajes de pesadilla que gesticulan ferozmente. 
Mundo baudeleriano, inspiró a Baudelaire:

"Goya, pesadilla llena de cosas desconocidas, de fetos que se cosen en medio de alquelarres, de viejas que se miran al espejo y de muchachas desnudas que, para tentar a los demonios, se estiran las medias".

El psicólogo se siente enormemente atraído por estas manifestaciones artísticas. Su curiosidad se excita ante el misterio que ellas han. significado siempre para los comentadores. Cada uno de ellos ha tratado de explicar algo, de justificarlo, de reducirlo a la razón y muchos tratan de creer que lo han hecho. Juan de la Encina, entre otros, habla del "humor" de Goya. Nada hay de humorismo en estas obras, sin embargo. Hay horror, amargura, desazón, angustia. Malraux lo ha visto claro: "Sin duda - dice- es el más grande intérprete de la angustia que haya conocido el occidente". Otros buscan significados, claves. Reconocen algunos de los personajes : figuras de la Corte o del Clero, la Duquesa de Alba, la Reina, y creen explicarlo todo por la intención punzante que trataría de herir, un poco a mansalva. Estos intentos son pobres frente a la realidad profunda de la obra. No puede negarse que en algunos casos hubo relación consciente con la actualidad, pero ella es superficial. Hay algo más profundo, una razón hasta ahora desconocida y que Aldous Huxley entrevé al decir : "¿Qué significan estas cosas? Y quizás la respuesta a ese interrogante es aue no tienen significado, en el sentido ordinario de la palabra; que se refieren a acontecimientos estrictamente privados, que ocurren en los niveles más oscuros de la mente de su creador".

El asombro y el miedo qlevancanos estudiosos a dudar de la normalidad de estas creaciones. "Lucifer, Belcebú y Legión fueron los maestros", dice Mc Coll y Stokes: "Debe ser un sobrevivir de lo que los revivalistas llaman "el viejo Adán", la naturaleza pecadora del hombre, que puede ser reprimida pero nunca totalmente erradicada". Guerlin se acerca aún más a la realidad: "Estas visiones - dice- son sobre todo las alucinaciones de un soñador que no ha abdicado su lucidez de artista. Fantasmas venidos de lo más profundo del inconsciente, continúan persiguiendo al artista cuando él ha retomado la posesión de sí mismo y se esfuerza por librarse de la impresión trágica". Y Huxley añade : "Estamos en un mundo de demonios, brujas y familiares, medio horrible, medio cómico, pero completamente inquietante, tanto que revela lo que ocurre en las escuálidas catacumbas de la mente humana".

Para tratar de comprender la obra, el psicólogo busca comprender al hombre. Desgraciadamente poco o nada se sabe de la familia y de la niñez de Goya. De sus años mozos sólo nos quedan leyendas de actividades eróticas, de líos con la justicia y la Inquisición, de afán de 
aventura tan sugestivas que han llevado a muchos autores, como Chapman y Scheneider, a hacer novelas de su vida, novelas que se entretienen en episodios de superficial atracción romántica o galante, sin penetrar en la complicada psicología del personaje, tan llena de posibilidades.

Si esta vía de estudio se cierra, el psicólogo no tieno más que una abierta : el estudio de la obra misma. Nota, inmediatamente, la tajante diferencia que se encuentra entre la producción artística de Goya en sus años juveniles y la que llena la última etapa de su vida. Entre el pintor de los cartones para las tapicerías, tan llenos de color y de esa alegría pujante de España y el que realizara los grabados, los frescos de la "Casa del Sordo" y las "Pinturas Negras" hay una enorme diferencia. $Y$ esto ya es un detalle psicológicamente interesante. ¿Qué pasó en el artista que produjo este cambio tan decisivo? ¿Puede ello darnos alguna luz para la interpretación de las pinturas mismas?

No podríamos avanzar un paso más en este camino si no contáramos con armas de estudio que nos permitieran un análisis profundo do la obra y nos dieran la oportunidad de deducir de él algunas características del hombre. Freud, el creador del psicoanálisis, no sólo produjo una revolución en la psicología y en la psiquiatría sino que influyó en todas las ciencias del espíritu y nos dió esas armas para penetrar en la urdimbre más profunda del espíritu humano y sacar las deducciones que esa penetración nos permite.

Sabemos bien que el psicoanálisis distingue en la psicología humana dos campos diferentes, pero estrechamente relacionados : por una parte, la consciencia, lo que sabemos de nosotros, lo que está a nuestro alcance y nuestra lógica maneja y, por la otra, el inconsciente, región oscura, desconocida para nuestro saber intelectual, región vaga, tenobrosa y oculta en la que se mueven las fuerzas instintivas en un ebullir de tendencias reprimidas que pugnan por salir a la consciencia, invadirla y dominarla. El psicoanálisis, pues, trata de, dirigiéndose al conocimiento de esa región inconsciente, comprender, a través de ella, las manifestaciones exteriores que, de otra manera, quedarian oscuras. Frente a la obra de arte trata, no de interpretar lo que el artista quiso, lúcida y conscientemente, expresar, sino de descubrir cuáles fueron los impulsos que, desde ese inconsciente misterioso y oscuro, determinaron precisamente que en ese momento el artista se expresara de esa manera. Parte de la base de que ninguna manifestación humana, y, por supuesto, la obra de arte menos que ninguna, está libre de esas poderosas fuerzas inconscientes que determinan nuestra vida y nuestra muerte. He aquí que Goya nos ofrece en las series de sus grabados y de sus di- 
bujos la oportunidad de esa penetración, si bien indiscreta e iconoclasta, sugestiva y apasionante.

Desgraciadamente, el psicoanálisis es un buceador de los abismos más hórridos del espíritu humano. Pretende penetrar en los entretelones de nuestro existir $y$, por supuesto, se encuentra con todo lo sórdido, bajo, vulgar, salvaje, y quizás sub-humano que todavía existe en el fondo del hombre. Su tarea es ingrata y desagradable. Es por eso que con cierto pudor me decido a emprender esa tarea delante de vosotros. Vamos, quizás, a penetrar hasta el punto donde lo más alto del hombre se confunde con lo más bajo, a esa raíz de la obra y del autor llena de perspectivas dantescas. Hagámoslo sin prejuicio y sin temores, y ensuciémosnos un poco las manos si queremos sacar del fondo, a costa ds esa suciedad, la redentora luminosidad del conocimiento.

¿Qué significa este mundo extraño que se ve en la obra goyesca? El mismo pintor trató varias veces de explicarlo y de justificarse. "Pero también merece aplauso, dice, el que se aleja completamente de la Naturaleza y consigue poner ante nuestra vista, formas y movimientos que existieron hasta entonces sólo en su imaginación".

Debemos preguntarnos: ¿Cómo llegaron a su imaginación? pregunta que nos hacemos, indudablemente, frente a todo artista y cuya respuesta, completamente satisfactoria, nunca podremos obtener. En el caso de Goya la investigación es tentadora porque el pintor parece ofrecernos en las obras a que nos estamos refiriendo, algo extraído de su yo profundo e invitarnos a explorar, a través de ese algo, inquietante y absurdo, los abismos inconscientes dondevaebe hallarse una do las fuentes de la inspiración.

Goya nos dice algo de lo poco que él mismo sabía. La placa 43 de la serie de los Caprichos, placa que reproduce, variando algo la composición, un dibujo previo, muestra al pintor dormido sobre su pupitre, mientras una serie de pájaros extraños revolotean a su alrededor y lo miran con ojos obsesionantes y un gato, como sólo los gatos de Goya pueden ser " está acostado a sus pies. Bajo el pupitre se lee una inscripción que es una clave: "El sueño de la razión produce monstruos".

Sí, el sueño de la razón da salida a los monstruos que, agazapados en el inconsciente, imponen la absurda sinrazón de su fuerza instintiva. De allí la importancia de la obra que estamos comentando. Creo que, aparte de su valor técnico - sobre el que no estoy capacitado para opinar- cada una de estas manifestaciones del genio goyesco hace vibrar cuerdas ocultas en el alma del espectador que, primero disgutado, luego lleno de curiosidad, de asombro y de miedo termina por sentir la fascinación de esa irrealidad tan llena de profunda y angustiadora realidad. 
¿Soñó realmente Goya las escenas y los personajes de su obra? El parece afirmarlo. Existe una serie de dibujos a tinta china ( 264 y 271 y 276 de la colección del Museo del Prado) que reproducen personajes absurdos e inquietantes. El primero lleva una inscripción de mano del pintor: "Visión burlesca" y el siguiente: "Otra en la misma noche", luego: " $3^{a}$. en la misma", "4a en la misma", "6 con pesadilla", "7?", " 8 a" y " $^{\prime}$ a". Hay otros dibujos, como el titulado "Mal Sueño" en parecido estilo. ¿Fueron visiones o sueños? La diferencia no tiene mayor interés en este momento ya que en ambos casos estarían mostrando lo que el artista veía durante "el sueño de la razón".

Tratemos de penetrar en ese mundo y, para ello, estudiemos los dibujos y los grabados.

Los dibujos del Museo del Prado nos presentan la actividad do Goya desde 1796 hasta 1828 y podemos seguir en ellos su evolución y ver cómo el mundo asombroso de su inconsciente va asomándose y forzando su mano. Ese mundo se impone ýa abiertamente en las aguafuertes : los "Caprichos", serie de 80 placas publicada en 1808, los "Desastres de la guerra", 83 trabajos realizados entre 1820 y 1830; la "Tauromaquia", que aparece en 1824, y los "Disparates", 22 grabados terminados en 1828. A esta serie deben añadirse otras obras de la misma época y con el mismo estilo. Algunos de los dibujos parecen haber sido bocetos que sirvieron para las aguafuertes posteriores.

La contemplación de esstas ebras nos lleva a un mundo irreal, donde los personajes más estrafalarios realizan las açiones más absurdas, donde la noche y la muerte sirven de telón de fondo para la danza de brujas duendes y pájaros.

Intentemos acercarnos a ese mundo y analizarlo. Los seres que lo pueblan son inquietantes todos: hombres estúpidos, mujeres baratas, monstruos, parte humanos, parte animales entre los que se destacan principalmente las viejas y los pájaros.

Los pájaros de Goya son seres de horror. Entre los dibujos a lápiz encontramos uno típico (número 391 del Museo del Prado). Cuerpo, cabeza y garras de lechuza, pico fuerte y abierto, alas de murciélago y esos ojos grandes, duros agresivos que veremos mucho. Sobre él cabalga una mujer. Pero son los pájaros de los grabados los verdaderamente obsesionantes. Ya hemos visto, los del "Sueño de la razón", que se repiten en la placa 45 y, más horribles en la 46 y la 65 , en la 68 , en la 72 y la 75, para aparecer nuevamente en los "Proverbios o Disparates". Algunas veces esos pájaros son reemplazados por seres alados, monstruos con rasgos humanos y expresiones indescriptibles (placas 46, $48,51,58,66,69,70$ de los Caprichos). Al lado de estas figuras horri- 


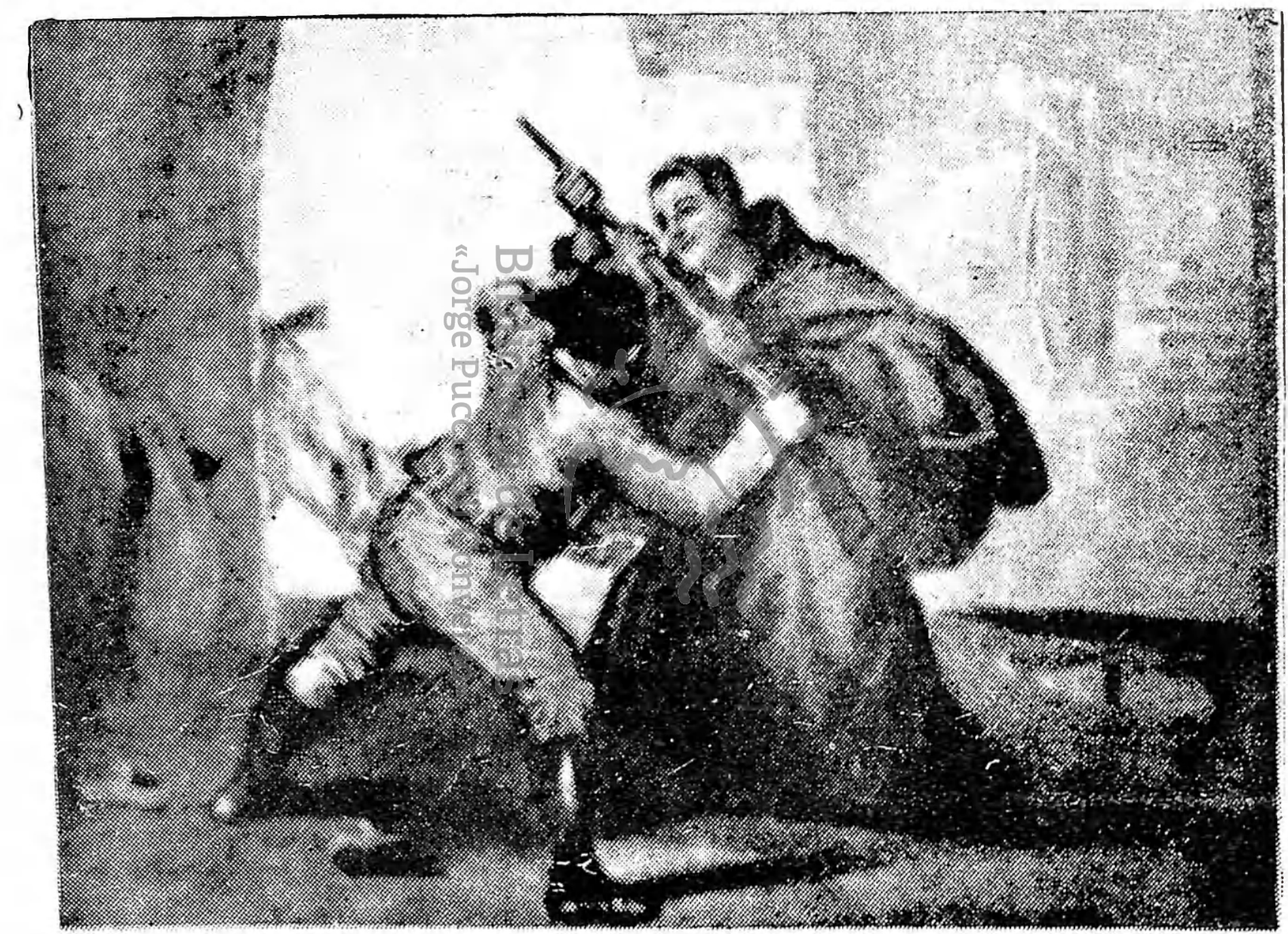

1806.-CAPTURA DEL LADRON MARAGATO

(Lucha por la posesión de la escopeta). 


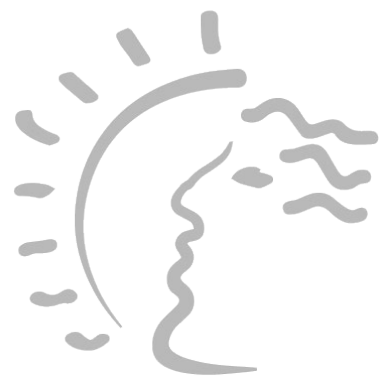

Biblioteca de Letras "Jorge Puccinelli Converso" 
bles, agresivas y brutales, Goya dibujó otra clase de aves muy diferentes : son esos infelices pajarracos a los que dos mujeres jóvenes y dos viejas echan a palos pues "ya van desplumados".

Los otros protagonistas son las viejas. Viejas simiescas, desdentadás, de arrugas repulsivas y actitudes equívocas; viejas deformes rodeando a muchachas fáciles o participando en alquelarres siniestros, donde se comen niños. Celestinas y brujas, las viejas de Goya desconocen todo lo que la edad puede poner de sereno, respetable y bello, en una mujer. No es difícil sospechar lo que estas figuras representan. En tres de los "Caprichos" el pintor da específicamente a sus viejas el papel de madre. En el 16 un ser, visto de espaldas, jorobado y miserable, enfrenta a una maja. La leyenda dice: "Dios la perdone: y era su madre". Y el comentario del mismo Goya explica: "La muchacha abandonó su hogar muy joven. Su noviciado fué hecho en Cádiz y de allá se fué a Madrid. Allí ganó la lotería. Está paseando en el Prado y una bruja sucia y horripilante le pide limosna. Ella la echa, pero la vieja la persigue. La insensible niña se vuelve y-quien lo creyerala pobre vieja era su madre".

La placa 31, muestra una joven en primer plano, estirándose las medias, mientras, al fondo, una vieja siniestra, envuelta en un manto, y con un rosario en la mano, "ruega por ella". El comentario del pintor dice : "Hace bien al hacerlo ..... que Dios.le dé suerte, la libre de sufrimientos, prestamistas y policías, que la haga hábil y cuidadosa, despierta y lista, como su santa madre"c. La placa 65 nos muestra una mujer gorda, desnuda, llevgda a cuestas por monstruos y escoltada por pájaros y gatos, los pájaros y gatos de Goya. La leyenda dice : "¿Dónde va mamá?" y el comentario: "Mamá está enferma, se va a pasear. Quiera Dios que sane".

Los pájaros de Goya son, claramente representaciones de instintos, pulsiones sexuales reprimidas. Revolotean alrededor de él, ensombrecen con sus alas todos los momentos y lo hipnotizan con sus ojos alucinantes. Ello es claro en algunos de los cuadros. En el "Capricho" numerado 20, que ya hemos visto, en el ángulo superior derecho hay dos pájaros claramente en un acto sexual. En la placa 72 cuatro monstruos alados persiguen a una mujer, mientras Goya comenta: "No te escaparás. Nadie se escapa cuando quiere ser cogido" y la placa 75 muestra una pareja atada por la cintura y las piernas, mientras un pájaro monstruoso se halla sobre ellos, pisando la cabeza de la mujer. Goya llama a este dibujo: "¿No hay quien los desate?", y glosa: "Un hombre y una mujer están atados. Tratan con toda su fuerza de libertarse y piden ayuda. Si no me equivoco son dos personas que se casaron a 
la fuerza". En varios casos (placas 48 y 65 de los Caprichos, dibujo número 391 del Museo del Prado) una cabeza de pájaro ocupa el lugar de los órganos sexuales de algún personaje de alquelarre.

Pero, sin embargo, en la acción de estos personajes, poco hay de genital. La intención de muchos de ellos lo es, pero predominan más bien manifestaciones desviadas del instinto.

$Y$ aquí debemos recurrir, nuevamente, a los conocimientos psicoanalíticos y meternos en ese mundo desagradable y siniestro de la vida instintiva profunda. Para el psicoanálisis la sexualidad engloba muchas actividades que son distintas de la normal. Entre ellas hay manifestaciones que se relacionan con otras funciones fisiológicas, como la defecación. No puedo, y no quiero, entrar en esta oportunidad al estudio detenido de estos descubrimientos psicoanalíticos pero, arriesgando el exponerme a la justificada reacción de disgusto y rechazo que el tratar estos temas produce, tengo que referirme a ellos ya que es la única manera de alcanzar una comprensión de los que Goya expresaba, in. conscientemente, en su producción artística.

En los grabados hay una serie de manifestaciones relacionadas claramente con lo que el psicoanálisis llamara erotismo anal. La placa 19 de los "Caprichos" es clara. En la número 25 un niño con las nalgas desnudas es azotado por una vieja con feroz expresión; en la 26 dos mujeres semi-desnudas se han puesto sillas en la cabeza. Goya comenta: "Ya tienen asiento". La placa 58 tiene la inscripción: "Trágala perro" y es de notar lnuevamentel la expresiónadel personaje, portador de una enorme jeringar que repile la intención de, la placa 19. En ia 17 de los "Disparates", en medio de varios personajes inverosímiles se halla uno, en la sombra, acurrucado, con otra gran jeringa en las manos y en la 19 de la misma serie hay un gigante con un palo enhiesto, mientras otro, en el primer plano, se proteje el ano. Para no citar más que los de significado obvio, me referiré a otro grabado, nombrado: "Le clystére", por Delteil, donde un mono levanta la cola de otro mientras un tercero se prepara a ponerle un enema con una jeringa.

Hay muchos otros ejemplos de esa insistencia en lo anal, como el dibujo 292 del Museo del Prado que tiene por título: "Edad con desgracias" y muesira a un viejo con los pantalones bajos y claras muestras de incontinencia fecal.

¿Por qué esa insistencia en el mismo tema? Para el psicoanálisis el significado es claro, significado que se confirma si contemplamos otro aspecto de estas obras: el sadismo. En todas las series, pero especialmente en los "Desastres de la Guerra", campea un sadismo horripilante. Goya se goza en los detalles más terribles : cuerpos despedazados, 
empalados, colgantes; miembros y cabezas aparte, sangre, destrucción, violencia inenarrable. En la placa 28 , un personaje con expresión verdaderamente libidinosa, se prepara a introducir una pica en el ano de otro que yace desnudo boca abajo; en la placa 33 dos soldados separan las piernas de un hombre sin ropas, mientras un tercero corta el periné con una espada. Y este sadismo impregna todas las series : duelos en los dibujos del Prado, monstruos que comen seres humanos, brujas que se preparan a devorar niños, él se muestra crudamente a través de toda su evolución.

Tratemos de buscar, en una visión sintética un camino de comprensión de esas características de la obra goyesca. Sabido es que el psicoanálisis considera que el mecanismo de sublimación instintiva juega un papel importante en la producción artística. En este caso ello no puede negarse. Que Goya daba salida en esas obras a impulsos inconscientes, es claro. Como Malraux lo hace notar, dibujaba sin plan previo y, solamente después de terminado el trabajo, buscaba un nombre para subrayarlo. Y lo que produjo confirma claramente lo que la teoría freudiana había ya señalado en manifestaciones tan distintas como la niñez, la neurosis y la caracterología. El psicoanálisis afirma, que, antes de llegar a la madurez del instinto sexual, el ser humano pasa por una serie de etapas inmaduras en las cuales su placer está fijado en distintos órganos y sistemas. Una de esas etapas es la llamada, precisamente, la anal-sadista, en la que las manifestaciones libidinosas se encuentran en el sadismo y en el èrotismo anal.

$\mathrm{He}$ aqui, pues, que la obra que estamos comentando nos permite descubrir en el artista características perfectamente definidas que nos autorizan a considerarlo como un individuo cuya evolución instintiva, imperfecta e inmadura, sufrió fijación en una de las etapas por las que el instinto sexual pasa antes de llegar a la normalidad adulta. Freud describió con el nombre de carácter anal, precisamente, los rasgos de personalidad de algunos individuos que presentan esta inmadurez: se trata de personas irritables, gruñones, puntillosas, terriblemente ahorsativas y obstinadas. Estos calificativos pintan a Goya y confirman nuestro diagnóstico.

Pero, una pregunta viene inmediatamente a la imaginación. ¿Cómo puede haber sido Goya un inmaduro sexual, un individuo fijado en etapas no adultas de la evolución instintiva cuando sabemos que fué un libertino, famosos por sus aventuras galantes y por su erotismo genital? Creo que ello, en lugar de ser una objeción, confirma nuestras suposiciones. En muchos casos de fijación sádico-anal los impulsos correspondientes a esta etapa quedan reprimidos en el inconsciente, mientras cons- 
cientemente son compensados por una actividad genital notable. Este equilibrio, sin embargo, es muy inestable y se rompe cuando cualquier acontecimiento de la vida altera las condiciones artificiales en que se desarrollaba. Goya fué un libertino, sí, y compensó con unos fuegos artificiales de actividad genital la real inmadurez de su evolución libidinosa. Pero cuando, los últimos años de su vida, se altera bruscamente toda su situación, cuando la Duquesa de Alba muere en 1802 y, en 1804, desaparece también la esposa, Goya casi sordo, amargado, y asqueado de la vida que hasta entonces había llevado, se hace más reconcentrado y su mundo se pueblo de fantasmas. No es difícil comprender cómo, ante la desaparición de las dos figuras señeras de su vida genital, se destruye su inestable estructura libidinosa y aparece una regresión a la etapa anal-sádica y, con ella, el impulso a dibujar y pintar como lo hizo. Es el retorno de lo reprimido.

Comienza así el camino de su introversión, de su volverse hacia su propio inconsciente y dejarse dominar poco a poco por los fantasmas que de él venían. La pulsión inconsciente guía su mano hacia la creación de un mundo mágico e incomprensiblé, mundo pre-categorial y absurdo, que nos recuerda el del esquizofrénico. La regresión continuaba y fué interrumpida sólo por la muerte.

He hablado de esquizofrenia y ello podría hacer pensar en una sugestión diagnóstica. Nada más lejano de mi intención. Aparte de sus obras no sé que haya en Goya algo que nos haga pensar en una enfermedad mental definida. buscándozdatos a través de la abundante bibliografía he podido apenas hallar vagasiveferencias. Guerlin dice: "Durante toda su vida estuvo, en efecto, sujeto a singulares crisis nerviosas. Pasaba sucesivamente por períodos de excitación enfermiza y depresiones prolongadas". Zapater refiere que le decía que pidiera a la Virgen le concediera ganas de trabajar, porque estaba muy deprimido. Estarico insiste sobre el insomnio pertinaz de sus últimos años; Mayer expresa: "Goya sufrió de irritabilidad nerviosa, que tomó la forma de falta de interés en el trabajo" y Gómez de la Serna refiere : "Don Francisco está enfermo, agravado aquél mal misterioso que le había de matar varias veces y que él llamaba "el insulto", especie de ataque cerebral contra el que solía usar la valeriana".

¿De qué murió Goya? Nadie lo sabe aún. Los diferentes médicos que han tratado de estudiar los síntomas y las características de su mal no han logrado ponerse de acuerdo. Muchos de ellos creen descubrir como causa fundamental de sus transtornos una vieja lués, adquirida en sus años juveniles. 
¿Luético? ¿Maníaco-depresivo? ¿Epiléptico? ¿Esquizofrénico? Sería ridículo tratar de encasillar su arte en estrechos marcos. Creo que fué un inestable, hipersensitivo y atormentado como, por otra parte, casi todos los genios artísticos.

No terminaré sirı hacer una aclaración. Así como, al decir que una estatua fué hecha de barro o que el bronce de otra salió de fundir deshechos, no pretendemos desmerecer la obra de arte ni explicar el milagro de su realización, así, al estudiar ciertos aspectos del mecanismo psicológico de la producción genial no creo haber descubierto el secreto de su génesis. Millones de seres arrastran por el mundo una fijación anal-sádica y millones regresionan a niveles inmaduros de la evolución libidinosa, pero sólo ha habido un Goya que supo hacer de ello escalera para elevarse hacia lo sublime.

Y esto nos lleva a considerar otro aspecto importante. La obra motivo de estas líneas fué grande, original, poderosa, pero ¿fué bella? El dar respuesta a este interrogante sería penetrar en la filosolía de la Estética. Nos contentaremos repitiendo la profunda frase con que Hans Sachs corona su estudio sobre "Belleza, Vida y Muerte" : "Beauty is life dancing-but dancing to the tune of death".

\section{Biblioteca de Letras "Jorge Puccinelli Converso"}

